\title{
Efeito da concentração de Estanho em Catalisadores Pt-Sn/C na Oxidação Eletroquímica de Etanol
}

\author{
F.E. LÓPEZ-SUÁREZ¹, C. T. CARVALHO-FILHO ${ }^{1}$, A. BUENO-LÓPEZ² ${ }^{2}$, K. I. B. EGUILUZ ${ }^{1}$, G. \\ R. SALAZAR-BANDA ${ }^{1}$ \\ 1 Universidade Tiradentes, Instituto de Tecnologia e Pesquisa / Laboratório de Eletroquímica e \\ Nanotecnologia. \\ ${ }^{2}$ Universidad de Alicante, Departamento de Química Inorgánica / MCMA \\ E-mail para contato: franzedwin@gmal.com
}

\begin{abstract}
RESUMO - Uma série de catalisadores de Pt-Sn/C foram sintetizados com diversas proporções atômicas de Pt: Sn (1:1), (2:1) e (3:1) pelo método de redução química, usando ácido fórmico como agente redutor. A interação dos dois metais está relacionada com a quantidade de Pt presente na composição do catalisador e, portanto, tem uma forte influência nas propriedades físicas e químicas dos catalisadores, assim como também na sua atividade eletroquímica. O catalisador preparado com uma relação 2:1 mostrou a melhor atividade a baixos potenciais. O comportamento observado é atribuído ao mecanismo bifuncional que o Sn exerce sobre a platina e/ou ao efeito ligante exercido pelo Sn nos átomos de Pt vizinhos. Os catalisadores são caracterizados por difração de raios $\mathrm{X}$, microscopia eletrônica de transmissão e voltametria cíclica. Os estudos de oxidação de etanol foram realizados em $0,5 \mathrm{M}$ de etanol.
\end{abstract}

\section{INTRODUÇÃO}

A crescente demanda e a intensa dependência de recursos energéticos fazem necessário o surgimento de processos alternativos para um abastecimento e aproveitamento muito melhor dos recursos energéticos. Além disso, deve-se considerar que os recursos derivados do petróleo têm um alto teor danoso para o meio ambiente. As células de combustível são dispositivos eletroquímicos que convertem diretamente energia química armazenada em um combustível, como hidrogênio ou alcoóis, em energia elétrica. Já se encontram no mercado células de combustível com eficiência elétrica de $40 \%$ e eficiência total (elétrica + térmica) superior a $85 \%$, aproveitando-se, também, o calor gerado pela própria célula (co-geração) como foi apresentado por Andújar e Segura (2009). O aumento da eficiência das células a combustível está fortemente ligado à eficiência do eletrocatalisador. Os eletrocatalisadores mais eficientes são confeccionados na forma de nanopartículas e comumente suportados em carbono, isto porque o carbono apresenta alta área superficial, alta condutividade e estrutura porosa. Porém, o carbono não facilita a catálise, apenas atua como suporte para os eletrocatalisadores e facilita a difusão dos gases como foi apresentado por Lee et al. (2008) .

Catalisadores binários contendo Pt-Sn suportados sob carbono tem sido descritos como os mais eficientes para a oxidação eletroquímica de etanol, quando são comparados com outros catalisadores binários (Antolini, 2007 e Zhou et al., 2003). Zignani et al. (2012) desenvolveram catalisadores 


\section{9 a 22 de outubro de 2014 \\ Florianópolis/SC}

contendo Pt-Sn suportados em carbono pelo método de ácido fórmico, sendo os principais produtos formados durante a oxidação de etanol ácido acético e acetaldeído. Os resultados mostrados por eles indicam que a seletividade e, portanto, a intensidade de corrente depende da quantidade de Sn no catalisador.

Assim, o objetivo deste trabalho foi sintetizar uma série de catalisadores de $\mathrm{Pt}-\mathrm{Sn} / \mathrm{C}$ por um processo de deposição usando ácido fórmico como agente redutor estudando o efeito da quantidade de estanho nos catalisadores Pt-Sn sobre as atividades eletrocatalíticas na oxidação eletroquímica de etanol.

\section{EXPERIMENTAL}

\subsection{Síntese e caracterização dos eletrocatalisadores Pt-Sn/C.}

Os catalisadores foram sintetizados por um processo de deposição usando ácido fórmico como agente redutor como tem sido mostrado por Colmati et al. (2005). Uma massa apropriada de substrato de pó de carbono N330 (Alfa Aesar), $75 \mathrm{~m}^{2} \mathrm{~g}^{-1}$ foi suspenso em uma solução de ácido fórmico. A suspensão foi aquecida ate $90^{\circ} \mathrm{C}$. Uma solução composta pelos dos precursores, ácido cloroplatínico e cloreto de estanho (Sigma Aldrich, purity > 98\%) foram lentamente adicionados à suspensão de carbono. A suspensão foi deixada por um tempo determinado e depois foi esfriada até a temperatura ambiente. $\mathrm{O}$ sólido foi filtrado, lavado e secado num forno a $60{ }^{\circ} \mathrm{C}$ durante 12 horas. Os materiais continham $20 \%$ em massa de metais no catalisador com diferentes teores de Pt:Sn, 1:1 ( $\left.\mathrm{Pt}_{1}: \mathrm{Sn}_{1}\right), 2: 1$ $\left(\mathrm{Pt}_{2}: \mathrm{Sn}_{1}\right)$ e $3: 1\left(\mathrm{Pt}_{3}: \mathrm{Sn}_{1}\right)$. O catalisador $\mathrm{Pt} / \mathrm{C}$ foi sintetizado da mesma forma na ausência de $\mathrm{Sn}$, é usado como material de referência.

O catalisador com maior eficiência foi caracterizado por difração de raios X (DRX) operando em um difratômetro Seifert powder com a radiação $\mathrm{CuK}_{a}(\lambda=0,15418 \mathrm{~nm})$. Os difratogramas foram registrados em ângulos $2 \theta$ desde 20 ate $80^{\circ}$, com um tamanho de passo de $0.02^{\circ}$ em um tempo de 3 segundos. Informações sobre a composição foram obtidas por meio de energia dispersiva de raios $\mathrm{X}$ (EDX). A morfologia e distribuição das partículas foi obtida por análises das microfotografias obtidas por microscopia eletrônica de transmissão (MET) usando um microscópio JEOL (JEM-2010) operando a $200 \mathrm{kV}$.

\subsection{Caracterização e oxidação eletroquímica de etanol nos eletrocatalisadores Pt- $\mathrm{Sn} / \mathrm{C}$.}

A caracterização e oxidação eletroquímica de etanol foram realizadas numa célula com três eletrodos conectada a um potenciostato/galvanostato Autolab modelo PGSTAT302N.

O eletrodo de trabalho usado como substrato foi uma placa de diamante dopado com boro. Os catalisadores $\left(3.6 \mu \mathrm{g}_{\text {metal }} / \mathrm{cm}^{2}\right)$ foram depositados no eletrodo por meio de uma suspensão aquosa produzida por dispersão de $0,008 \mathrm{~g}$ do material em solução de Nafion ${ }^{\circledR} 0,5 \%$ (Aldrich) mais $1000 \mu \mathrm{L}$ de água ultrapura, seguida de agitação em ultrassom de banho por 30 min secado na estufa a $60{ }^{\circ} \mathrm{C}$ 
por $10 \mathrm{~min}$. Como contra-eletrodo foi utilizada uma placa de Pt de $0,5 \mathrm{~cm}^{2}$ e como eletrodo de referência utilizou-se o eletrodo de hidrogênio na mesma solução (EHMS) que se encontrava imerso em um capilar de Luggin.

A atividade eletroquímica foi estudada na ausência, caracterização eletroquímica, e na presença de etanol, oxidação eletroquímica, em soluções de $0.5 \mathrm{M} \mathrm{H}_{2} \mathrm{SO}_{4}$ e $0.5 \mathrm{M} \mathrm{C}_{2} \mathrm{H}_{5} \mathrm{OH}$, respectivamente. A voltametria cíclica foi utilizada para avaliar o comportamento de cada catalisador em uma janela entre 0,0 and 1,3 V (vs. EHMS) aplicando uma velocidade de varredura de $20 \mathrm{mV} \mathrm{s}^{-1}$. Experimentos foram realizados para obter curvas de polarização em estado quase estacionário em um intervalo entre 0,2 e $0,8 \mathrm{~V}$ (vs. EHMS) polarizando por 200 segundos a cada $20 \mathrm{mV}$.

\section{RESULTADOS E DISCUSSÃO}

\subsection{Caracterização e oxidação eletroquímica de etanol nos eletrocatalisadores.}

A Figura 1 mostra as curvas de voltametria cíclica dos eletrocatalisadores sintetizados no eletrólito de suporte. Observa-se para os eletrocatalisadores $\mathrm{Pt}_{1}: \mathrm{Sn}_{1}$ e $\mathrm{Pt}_{2}: \mathrm{Sn}_{1}$ que a região de adsorção-dessorção de hidrogênio (0,05-0,4 V vs. EHMS) apresenta-se pouco definida e também se observa um aumento dos valores de corrente na região de dupla camada 0,4-0,8 V (vs. EHMS) quando é comparado com os catalisadores $\mathrm{Pt}_{3}: \mathrm{Sn}_{1}$ e $\mathrm{Pt} / \mathrm{C}$. No entanto, o voltamograma cíclico do eletrocatalisdor $\mathrm{Pt}_{3}: \mathrm{Sn}_{1}$ apresenta uma região de adsorção-dessorção de hidrogênio tão definida quanto a do catalisador $\mathrm{Pt} / \mathrm{C}$, o que sugere que este material pode apresentar uma superfície mas rica em Pt.

A Figura 2 retrata os voltamogramas cíclicos dos catalisadores de Pt:Sn $(1: 1,2: 1$ e 3:1) na presença de etanol. Os voltamogramas obtidos para a eletrooxidação do etanol são típicos de sistemas que envolvem mais de uma etapa de reação, evidenciado no comportamento de aumento e diminuição da densidade de corrente, que representam processos de formação e consumo de espécies em uma interface eletroativa e/ou competição entre estas. Pode-se notar que os picos e as intensidades dos mesmos não seguem uma relação proporcional com a quantidade de $\mathrm{Pt}$ e $\mathrm{Sn}$, sugerindo uma influência de outros fatores além de razão em massa dos metais utilizados. $\mathrm{O}$ catalisador $\mathrm{Pt}_{2}: \mathrm{Sn}_{1}$ apresentou uma melhor atividade para a eletrooxidação de etanol a baixos potenciais e uma maior densidade de corrente. 


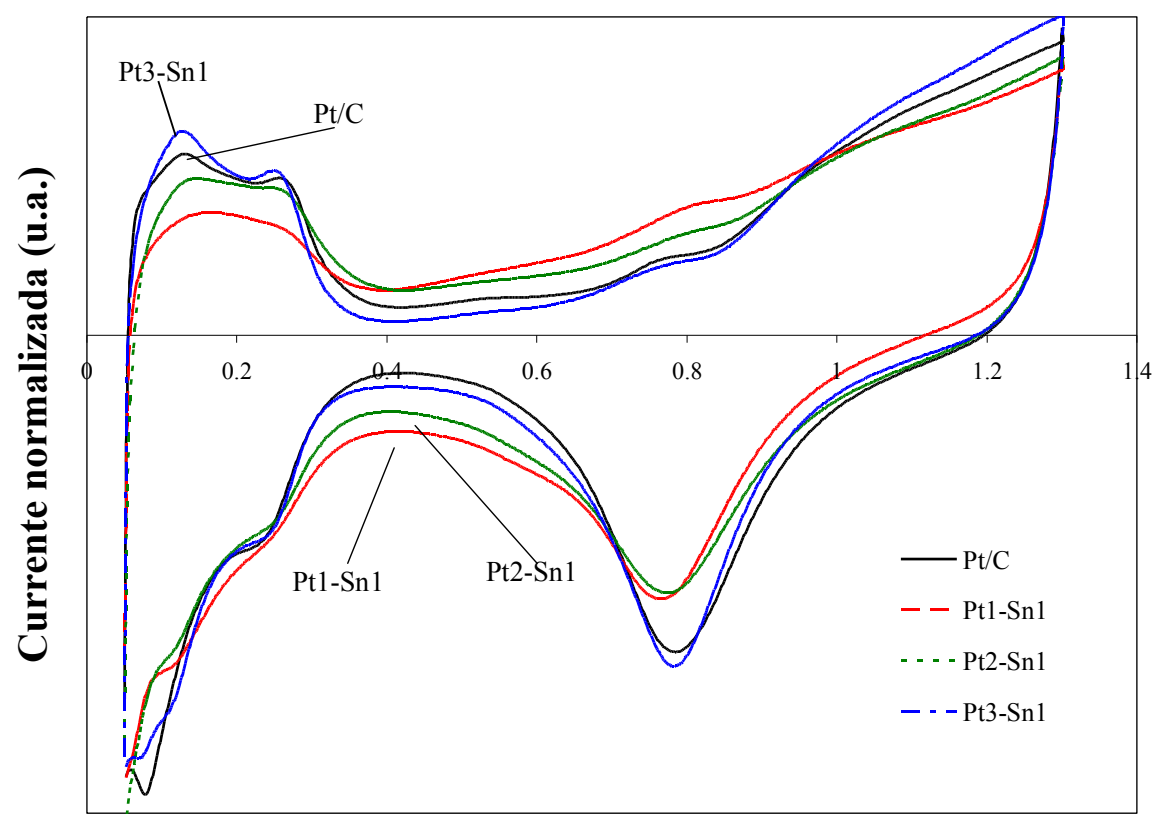

E (V) vs EHMS

Figura 1. Voltamogramas cíclicos obtidos nos eletrocatalisadores sintetizados por meio de uso do agente redutor ácido fórmico, obtidos em uma solução de $0,5 \mathrm{M} \mathrm{H}_{2} \mathrm{SO}_{4}$ com uma velocidade de varredura de $20 \mathrm{mV} \mathrm{s}^{-1}$.

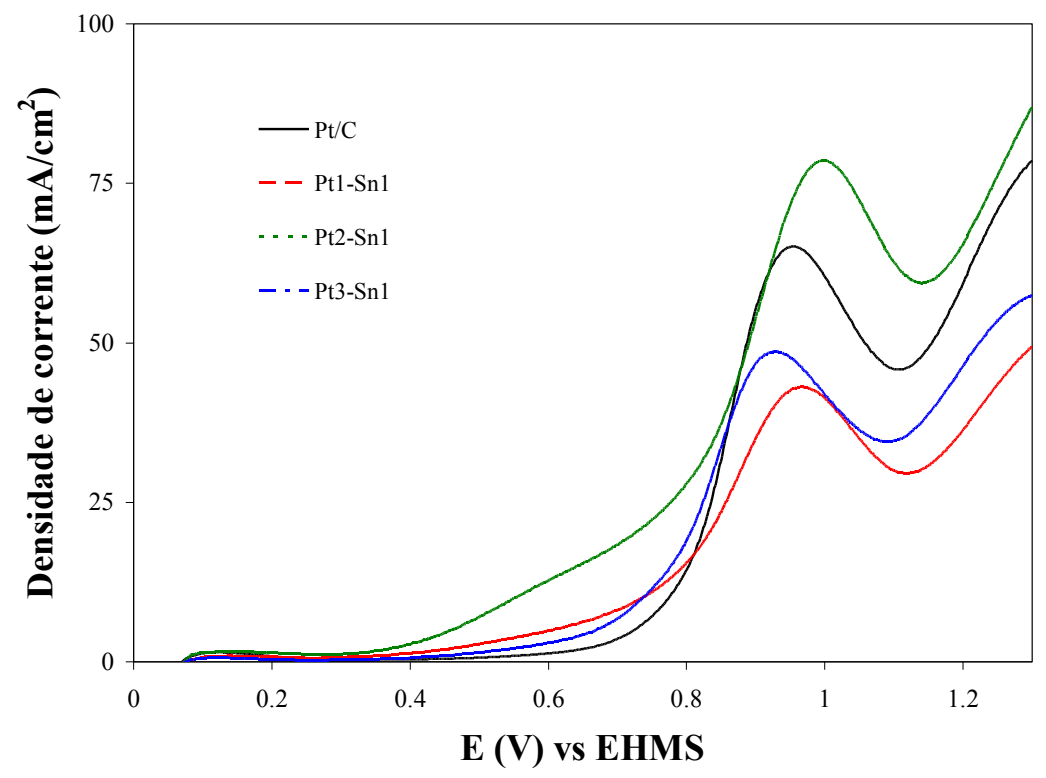

Figura 2. Voltamogramas cíclicos obtidos em solução de $0,5 \mathrm{M} \mathrm{H}_{2} \mathrm{SO}_{4}$ e $0,5 \mathrm{M} \mathrm{C}_{2} \mathrm{H}_{5} \mathrm{OH}, v=20$

$$
\mathrm{mV} \mathrm{s}^{-1} \text {. }
$$


$\mathrm{Na}$ Figura 3 são apresentadas as curvas de polarização anódicas para os eletrocatalisadores. O potencial de início da eletrooxidação de etanol sobre todos os catalisadores é deslocada negativamente em comparação com o catalisador $\mathrm{Pt} / \mathrm{C}$. Para toda a faixa de potencial estudada, o catalisador $\mathrm{Pt}_{2}-\mathrm{Sn}_{1}$ mostra a densidade de corrente mais elevada. Além de que, o catalisador $\mathrm{Pt}_{2}: \mathrm{Sn}_{1}$ tem uma quantia menor de $\mathrm{Pt}$, quando é comparado com o catalisador $\mathrm{Pt}_{3}: \mathrm{Sn}_{1}$, é estimado que o $\mathrm{Pt}_{2}: \mathrm{Sn}_{1}$ não atinge total recobrimento de $\mathrm{Pt}$ na superfície, deixando o $\mathrm{Sn}$ evidente e que em algum grau o $\mathrm{Sn}$ influencia o processo de eletro-oxidação do etanol. Assim, é possível assumir que a capacidade de remoção de hidroxilas que o estanho apresenta, já mostrado em outros estudos, Zignani et al. (2012), é relevante para o melhor resultado na eletrooxidação do etanol. Finalmente, o catalisador preparado com uma relação 2:1 mostrou a melhor atividade catalítica para a oxidação de etanol, especialmente a baixos potenciais. O comportamento observado é atribuído ao mecanismo bifuncional que o Sn exerce sobre a platina e/ou ao efeito ligante exercido pelo Sn nos átomos de $\mathrm{Pt}$ vizinhos

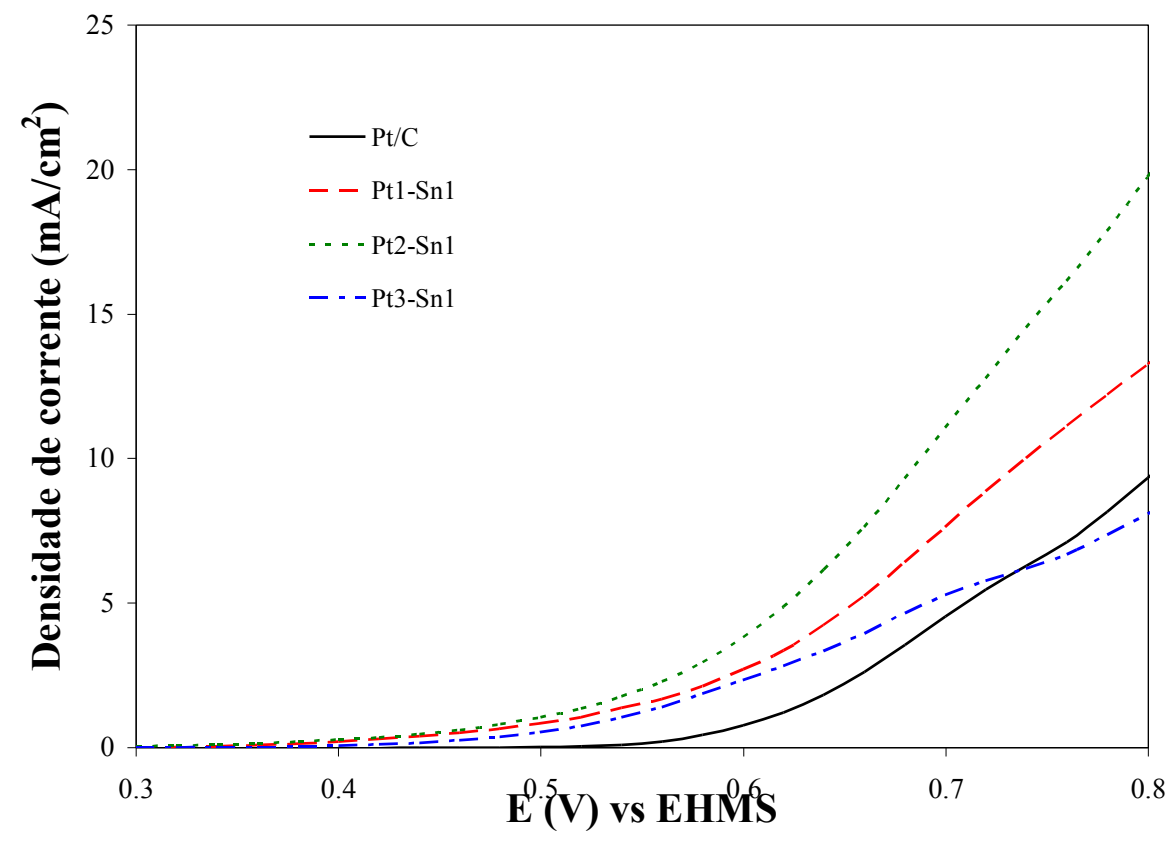

Figura 3. Curvas de polarização em $0,5 \mathrm{M}$ de $\mathrm{H}_{2} \mathrm{SO}_{4}$ e $0,5 \mathrm{M} \mathrm{C}_{2} \mathrm{H}_{5} \mathrm{OH}$

\subsection{Caracterização do eletrocatalisador $\mathbf{P t}_{2}-\mathrm{Sn}_{1}$.}

O catalisador $\mathrm{Pt}_{2}: \mathrm{Sn}_{1}$ que apresento o melhor comportamento foi caracterizado por DRX e MET. $\mathrm{Na}$ Figura 4 são mostrados os difratogramas de raios $\mathrm{X}$ dos eletrocatalisadores $\mathrm{Pt}_{2}: \mathrm{Sn}_{1}$ e $\mathrm{Pt} / \mathrm{C}$. $\mathrm{Na}$ Figura 4, observa-se que os picos no $2 \Theta=26^{\circ}$ e $44^{\circ}$ são associados com os planos (002) e (100) da estrutura cristalina do carbono usado como suporte. Para o catalisadores $\mathrm{Pt}_{2}: \mathrm{Sn}_{1}$ e $\mathrm{Pt} / \mathrm{C}$ observa-se os três picos de difração em aproximadamente $2 \Theta=39.9^{\circ}, 46.5^{\circ}$ e $67.8^{\circ}$ os quais são associados aos planos (111), (200), e (220), respectivamente, da estrutura cúbica de face centrada (CFC) de platina e suas ligas (Referencia JCPDS 04-0802 na Figura 4). Um pico no $2 \Theta=52^{\circ}$ é associado com a presença de fases de óxido da estanho $\left(\mathrm{SnO}_{2}\right)$, no entanto, não foi possível avaliar dos resultados 
obtidos pelo DRX na presença de Sn reduzido, entretanto, sua presença em quantidades menores ou na forma de óxidos amorfos não pode ser descartada.

Para o catalisador $\mathrm{Pt}_{2}: \mathrm{Sn}_{1}$ observa-se os mesmos picos que para o catalisador $\mathrm{Pt} / \mathrm{C}$, no entanto, estes se encontram deslocados para ângulos menores mostrando a formação de liga Pt-Sn para este material. As reflexões do plano (220) foram usadas para calcular o tamanho médio do cristalito através da equação de Scherrer e os valores encontrados foram: 7,0 nm para o $\mathrm{Pt}_{3}-\mathrm{Sn}_{1}$ e 5,2 nm para o catalisador $\mathrm{Pt} / \mathrm{C}$.

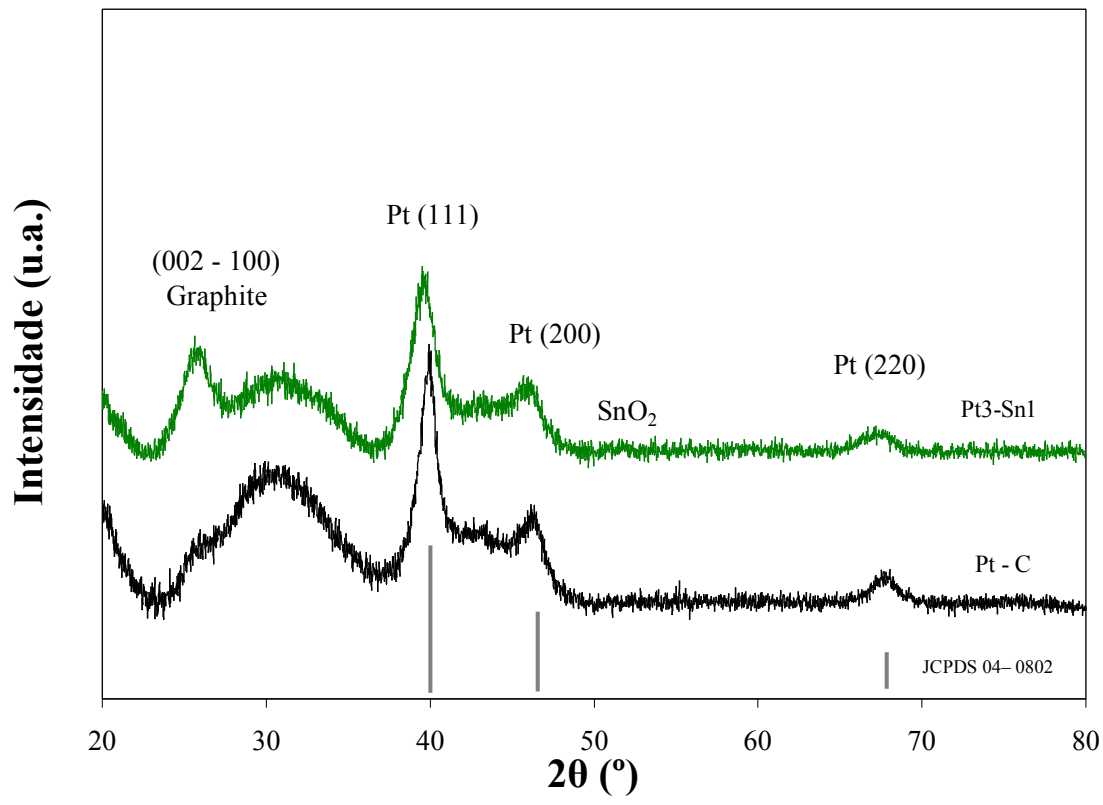

Figura 4 - Difratogramas de raios $\mathrm{X}$ dos eletrocatalisadores

As micrografias obtidas para o catalisador $\mathrm{Pt}_{2}: \mathrm{Sn}_{1}$ por meio do MET podem ser vistos na Figura 5 a-b. Observa-se na Figura 5a que pequenas partículas pretas de Pt se encontram dispersas sobre o suporte do carbono e que o método usado para a preparação de nanopartículas foi satisfatório. $\mathrm{Na}$ Figura 5b obtida usando uma maior ampliação, pode-se ver a ligação de Pt-Sn pela mudança de contraste. Por meio de análises por EDX foi possível determinar a composição de Pt e Sn, como uma relação atômica de Pt: 1,5 e Sn: 0,9, a qual é muito próximo ao valor nominal. 

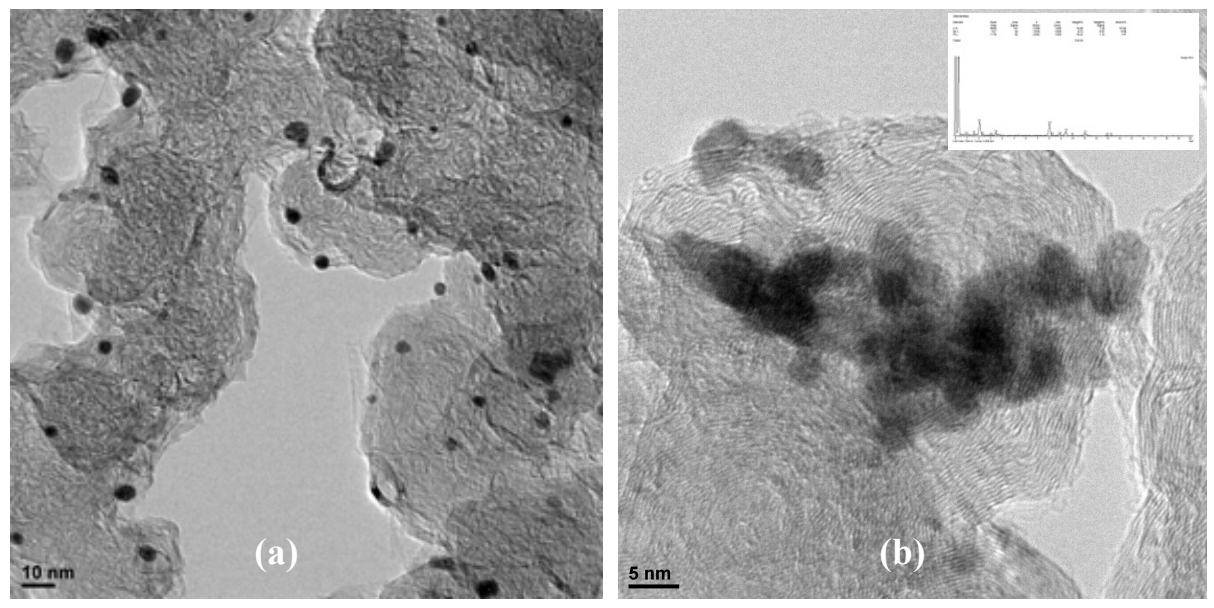

Figura 5 - Imagens de MET: (a) $\mathrm{Pt}_{2}-\mathrm{Sn}_{1}(10 \mathrm{~nm})$ e $\mathrm{Pt}_{2}-\mathrm{Sn}_{1}(5 \mathrm{~nm})$

\section{AGRADECIMENTOS}

Os autores dão os agradecimentos pela ajuda financeira do Conselho Nacional de Desenvolvimento Científico e Tecnológico- CNPq (projectos: 303630/2012-4, 402243/2012-9 e 310282/2013-6).

\section{CONCLUSÕES}

Uma série de catalisadores de Pt-Sn/C forram preparados com diversas propưrções atômicas de Pt:Sn (1:1), (2:1) e (3:1) pelo método de redução química, usando ácido fórmico como agente redutor. $\mathrm{O}$ catalisador $\mathrm{Pt}_{2}: \mathrm{Sn}_{1}$ apresentou o melhor desempenho, principalmente para potenciais abaixo de 0,5 $\mathrm{V}$ e com uma maior densidade de corrente. O comportamento observado é atribuído ao mecanismo bifuncional que o $\mathrm{Sn}$ exerce sobre a platina e/ou ao efeito ligante exercido pelo $\mathrm{Sn}$ nos átomos de $\mathrm{Pt}$ vizinhos.

\section{REFERÊNCIAS}

ANDÚJAR, J. AND F. SEGURA. Fuel cells: History and updating. A walk along two centuries. Renew. Sust. Energ. Rev., v.13, p. 2309-2322, 2009.

ANTOLINI, E. Catalysts for direct ethanol fuel cells. J. Power Sources, v. 170. p. 1-12, 2007.

Colmati, F.; Antolini, E.; Gonzalez, E. R. Pt-Sn/C electrocatalysts for methanol oxidation synthesized by reduction with formic acid. Electrochim. Acta, v.50, p. 5496-5503, 2005.

LEE, M. H.; DO, J. S., Kinetics of oxygen reduction reaction on $\mathrm{Co}_{\text {rich }}$ core $-\mathrm{Pt}_{\text {rich shell }} / \mathrm{C}$ electrocatalysts. J. Power Sources, v.188, p.353-358, 2009. 
ZHOU, W.; ZHOU, Z.; SONG, S.; LI, W.; SUN, G.; TSIAKARAS, P.; XIN, Q. Pt based anode catalysts for direct ethanol fuel cells. Appl. Catal. B-Environ., v.46, p. 273-285, 2003.

ZIGNANI, S. C.; GONZALEZ, E. R.; BAGLIO, V.; SIRACUSANO, S.; ARICÒ, A. S. Investigation of a $\mathrm{Pt}_{3} \mathrm{Sn} / \mathrm{C}$ Electro-Catalyst in a Direct Ethanol Fuel Cell Operating at Low Temperatures for Portable Applications. Int. J. Electrochem. Sc., v.7, p.3155-3166, 2012. 